\title{
PAPER
}

\section{Chronic pancreatitis and cystic fibrosis}

\section{H Witt}

Gut 2003;52(Suppl II):ii31-ii41

Recent discoveries of trypsinogen and trypsin inhibitor mutations in patients with chronic pancreatitis (CP) support the hypothesis that an inappropriate activation of pancreatic zymogens to active enzymes within the pancreatic parenchyma starts the inflammatory process. Current data suggest that $\mathrm{CP}$ may be inherited dominant, recessive, or complex as a result of mutations in the above mentioned or yet unidentified genes. Evaluation of patients with CP should include genetic testing. Cystic fibrosis (CF) is an autosomal recessive inherited disorder caused by mutations in the CF transmembrane conductance regulator (CFTR) gene and is characterised by pancreatic insufficiency and chronic bronchopulmonary infection. The progression and severity of pulmonary disease differs considerably between people with identical CFTR mutations and does not seem to correlate with the type or class of the CFTR mutation. The identification of further disease modifying genetic factors will increase the pathophysiological understanding and may help to identify new therapeutic targets.

This paper is dedicated to Michael Becker on his 59th anniversary.

Correspondence to: Dr H Witt, Kinderklinik, Charité-Campus

Virchow-Klinikum, Humboldt-Universität Augustenburger Platz 1 D-13353 Berlin, Germany; heiko.witt@charite.de

\section{CHRONIC PANCREATITIS}

In industrialised countries, chronic pancreatitis (CP) is caused by long term alcohol misuse in about $70 \%$ to $80 \%$ of cases. ${ }^{12}$ Other causes such as anatomical anomalies, hyperlipidaemia, and hypercalcaemia are rare. In $10 \%-30 \%$ of patients with CP there is no apparent underlying cause, including heredity, and these cases are classified as idiopathic CP. The clinical pattern of $\mathrm{CP}$ is characterised by an early stage with recurrent episodes of acute pancreatitis followed by a late stage including pancreatic calcifications, exocrine insufficiency, and diabetes mellitus in most patients. ${ }^{1}$ Clinically, chronic pancreatitis is characterised by recurrent or persisting abdominal pain, though the disease may present without pain. Morphologically, the pancreas shows an irregular sclerosis with focal, segmental, or diffuse destruction of the parenchyma. ${ }^{3}$ Abnormalities of the pancreatic duct system such as dilatations or strictures as well as intraductal plugs containing protein or calculi are frequent findings. The reported incidence of $\mathrm{CP}$ in industrialised countries has been estimated to about 3.5 to 10 per 100000 inhabitants. As most adult CP patients suffers from alcohol related disease, the epidemiological data published to date are not applicable to paediatric patients.

In 1952, Comfort and Steinberg reported that $\mathrm{CP}$ clusters in selected families, suggesting an inherited disease in these patients. ${ }^{4}$ The present paragraph of this review delineates the different genes involved in the pathogenesis of hereditary or idiopathic pancreatitis, the impact of these genetic discoveries on other types of CP such as alcohol induced $\mathrm{CP}$, and the implications for disease pathogenesis.

\section{Cationic trypsinogen (PRSS1)}

In 1896, Hans Chiari postulated that pancreatitis results from pancreatic autodigestion. An inappropriate conversion of pancreatic zymogens to active enzymes within the pancreatic parenchyma was proposed to initiate the inflammatory process. A key role has been attributed to the activation of trypsinogen to trypsin, converting all proteolytic proenzymes to their active form. ${ }^{6}$ Three different trypsinogens have been described in human pancreatic juice and have been designated, according to their electrophoretic mobility, as cationic trypsinogen, anionic trypsinogen, and mesotrypsinogen. ${ }^{7}$ Compared with the anionic isoenzyme, the cationic trypsinogen autoactivates more easily and is more resistant to autolysis. ${ }^{89}$

By microsatellite linkage analysis, several groups located a gene for hereditary pancreatitis on the long arm of chromosome 7 (7q35). ${ }^{10}$ Subsequently, a mutation in the cationic trypsinogen gene, also referred to as serine protease 1 (PRSS1), was identified as underlying defect by a candidate gene approach. In five families with $\mathrm{CP}$, a substitution of arginine by histidine at residue $122(\mathrm{R} 122 \mathrm{H})$ segregated with the disease. ${ }^{13}$ $\mathrm{R} 122 \mathrm{H}$ seems to be the most common PRSSI mutation observed worldwide. In subsequent studies, two other PRSSI mutations have been frequently described: a substitution of asparagine by isoleucine at codon 29 (N29I) ${ }^{14}$ and an exchange of alanine by valine at codon 16 (Al6V) ${ }^{16}$ The latter mutation is usually observed in patients with idiopathic $\mathrm{CP}^{16}$ In the following years, several other PRSSI mutations were reported: -28delTCC, D22G, K23R, N29T, P36R, G83E, K92N, L104P, R116C, R122C, V123M, and C139F. ${ }^{17-25}$ With the exception of R116C and $\mathrm{R} 122 \mathrm{C}$, these variations were found in single patients or families only, and a detailed clinical background was mostly not mentioned. Thus, their pathogenic significance remains largely to be elucidated.

Abbreviations: $\mathrm{CP}$, chronic pancreatitis; $\mathrm{CF}$, cystic fibrosis; CFTR, cystic fibrosis transmembrane conductance regulator; $M H C$, major histocompatibility complex; TNF $\alpha$, tumour necrosis factor $\alpha$; TGF $\beta$, transforming growth factor $\beta_{1}$; GSTM1, glutathione $S$ transferase $M 1$; NO, nitric oxide; $M B L$, mannose binding lectin; $C B A V D$; congenital bilateral absence of the vas deferens; $A B P A$, allergic bronchopulmonary aspergillosis 
Although the precise disease mechanisms have not been unravelled, it is now a generally accepted model that an increased intrapancreatic trypsin activity results in pancreatitis. Site directed mutagenesis of recombinant human cationic trypsinogen revealed that all of the mutations studied (N29I, N29T, R122H, and R122C) increased significantly autoactivation in vitro. ${ }^{26-30}$ Additionally, N29T, R122H, and R122C but not N29I inhibited autolysis of the enzyme. ${ }^{26-30}$ A study using synthetic peptides showed an increased hydrolysis rate of the D22G and the K23R variants compared with wild type, indicating that these mutations might also facilitate trypsinogen autoactivation. ${ }^{18}$ However, supporting data on recombinant enzymes are still lacking. To date, no experimental data exist on the functional consequences of the Al6V mutation. In summary, increased intrapancreatic trypsinogen activation may be the common initiating step of pancreatitis caused by PRSS1 mutations, whereas stabilisation of trypsin may be an accessory mechanism.

\section{Serine protease inhibitor, Kazal type 1 (SPINK1)}

The serine protease inhibitor, Kazal type l (SPINKI), also known as pancreatic secretory trypsin inhibitor (PSTI), is a potent antiprotease that is thought to be an important inactivation factor of intrapancreatic trypsin activity. SPINKl was first isolated in the bovine pancreas by Kazal and coworkers in $1948 .^{31}$ SPINKl possesses a reactive site that serves as a specific target substrate for trypsin. ${ }^{32}$ However, trypsin inhibition by SPINKl is only temporary because the trypsin-SPINKI complex itself serves as substrate for trypsin, resulting in a subsequent degradation of the inhibitor molecule and in restoration of the original trypsin activity. ${ }^{33}$

A considerable number of patients with hereditary CP do not show a PRSS1 mutation, ${ }^{16}$ suggesting that genetic defects in other genes might be involved in the disease pathogenesis. As "gain of function" mutations in the PRSSI gene cause pancreatitis by increased tryptic activity within the pancreatic parenchyma due to a "super trypsin", it was hypothesised that pancreatitis may also be raised by "loss of function" mutations in pancreatic trypsin inhibitors. By a candidate gene approach, the serine protease inhibitor, Kazal type 1 (SPINKl) was identified as another pancreatitis gene: in 18 of 96 unrelated paediatric patients, a substitution of asparagine by serine at codon 34 (N34S) was found..$^{34}$ Six patients were homozygous for this mutation. No phenotypic differences between heterozygous and homozygous N34S patients were detected. Compound heterozygosity of the N34S heterozygotes as well as gross deletions or insertions were excluded by analysing the complete intronic sequences after long range polymerase chain reaction. ${ }^{34}$ The association between N34S and CP was confirmed by others. ${ }^{35-38} \mathrm{~N} 34 \mathrm{~S}$ is mostly found in patients without a family history of CP: $15 \%-40 \%$ of patients with so called idiopathic CP carry N34S on one allele or on both alleles. ${ }^{35-38}$ Interestingly, N34S is in complete linkage disequilibrium with four other intronic sequence variants: IVS1-37 $\mathrm{T}>\mathrm{C}$, IVS2+268 A>G, IVS3-604 G>A, and IVS3-66 -65 insTTTT. ${ }^{34}$ This finding indicates that N34S is an evolutionary ancient mutation arisen a long time ago. So far, no experimental studies have elucidated the functional consequences of N34S.

In one CP family with multiple affected members, a heterozygous mutation disrupting the start codon (MIT) was detected. ${ }^{34}$ The mutation was found in the index patient, in the unaffected father, and in the affected grandfather. Moreover, the deceased great grandfather suffered from CP. This pedigree suggests that even a single SPINKI mutation may strongly contribute to the disease development. Additional SPINK1 mutations have been reported, mostly in single patients or families: $-215 \mathrm{G}>\mathrm{A},-53 \mathrm{C}>\mathrm{T},-4 \mathrm{lG}>\mathrm{A},-2 \mathrm{C}>\mathrm{A}, \mathrm{L} 14 \mathrm{P}, \mathrm{D} 50 \mathrm{E}$, IVS3 $+2 \mathrm{~T}>\mathrm{C}, \mathrm{IVS} 3+125 \mathrm{C}>\mathrm{A}$ and IVS3+184 T>A, R65Q, R67C..$^{34} 35$ 39-43

\section{Cystic fibrosis transmembrane conductance regulator} (CFTR)

Recently, two studies described an association between CFTR mutations and $\mathrm{CP}^{44}{ }^{45}$ The link between CFTR and CP is supported by the findings that both conditions may show abnormal sweat chloride contents ${ }^{46}$ as well as pancreatic ductal obstruction due to inspissated secretions. ${ }^{47}{ }^{48}$ Moreover, some patients with cystic fibrosis (CF) suffer from recurrent attacks of pancreatitis. ${ }^{49}{ }^{50}$

Sharer and coworkers tested 134 patients with CP, including 60 cases with idiopathic disease and 71 cases with alcohol induced CP, for 22 mutations and for the $5 T$ allele in intron $8 .{ }^{44}$ Eighteen patients ( $13.4 \%$ ), including 12 with idiopathic CP (20\%), were heterozygous for a CFTR mutation. Fourteen patients $(10.4 \%)$ had the $5 T$ allele in intron 8 . Four patients were heterozygous for both a CFTR mutation and the $5 T$ allele. The frequency of CFTR mutations in alcohol related CP was two times and in idiopathic CP four times the expected, whereas the frequency of the $5 T$ allele was not increased (allele frequency $0.05^{51}$ ). Cohn and coworkers investigated 17 CFTR mutations and the $5 T$ allele in 27 patients with idiopathic $\mathrm{CP}^{45}$ Seven patients $(25.9 \%)$ had at least one CFTR mutation and five patients ( $18.5 \%)$ had a $5 T$ allele. One patient was compound heterozygous for the $\Delta \mathrm{F} 508$ and the $\mathrm{R} 117 \mathrm{H}$ mutation and two patients were heterozygous for the $\Delta \mathrm{F} 508$ mutation and the $5 T$ allele. The frequency of CFTR mutations in idiopathic CP was six times higher than expected, whereas the frequency of the $5 T$ allele was twice as high. Both studies investigated the most common CFTR mutations only.

In more recent studies, Noone and colleagues and Audrézet and coworkers analysed the complete CFTR coding sequence and PRSSI and SPINKI in CP patients. ${ }^{43}{ }^{52}$ In both studies, 25\% to $30 \%$ carried at least one CFTR mutation (without $5 T$ allele), and several patients were compound-heterozygous for a CFTR mutation or were trans-heterozygous for a CFTR mutation and a mutation in SPINK1 respectively PRSS $1 .{ }^{43} 52$ These two studies illuminate the significance of a combination of different mutations in different genes in inherited pancreatitis.

\section{$\alpha_{1}$ Antitrypsin}

$\alpha_{1}$ Antitrypsin is a serum inhibitor of serine proteases such as neutrophil elastase, cathepsin G, and trypsin. Inherited $\alpha_{1}$ antitrypsin deficiency is associated with pulmonary emphysema and liver disease. Two frequent genetic defects lead to an $\alpha_{1}$ antitrypsin deficiency: a glutamine to valine substitution at codon 264 (E264V) (PiS) and a glutamine to lysine substitution at codon 342 (E342K) (PiZ). ${ }^{53}$

An association between $\alpha_{1}$ antitrypsin deficiency and CP has been suggested by several case reports and two systematic studies, ${ }^{5455}$ but conflicting results were obtained by other authors. ${ }^{56-58}$ All these studies, however, were performed by either $\alpha_{1}$ antitrypsin phenotyping or by measurement of serum concentrations and focused predominantly on alcohol induced pancreatitis. In two recent studies, $\alpha_{1}$ antitrypsin genotypes were investigated in 96 patients and 124 patients with non-alcoholic CP. ${ }^{59}$ In both studies, the frequencies of the $\alpha_{1}$ antitrypsin deficiency alleles PiS and PiZ did not significantly differ between patients and controls and were similar to the reported frequencies in Europe..$^{53}$ The lack of an association of $\alpha_{1}$ antitrypsin deficiency and pancreatitis in these studies is in line with the results of a follow up study in 246 Piz homozygous individuals in which no case of symptomatic pancreatitis was reported. ${ }^{61}$

\section{Complexity of the inheritance pattern}

Hereditary pancreatitis is usually defined as an autosomal dominant disease with a penetrance of $80 \%{ }^{62}$ The clinical characteristics of the most families with the R122H or the N29I mutation in the PRSSI gene are in line with this concept. In contrast, $\mathrm{Al} 6 \mathrm{~V}$ shows a low penetrance and is typically 
A

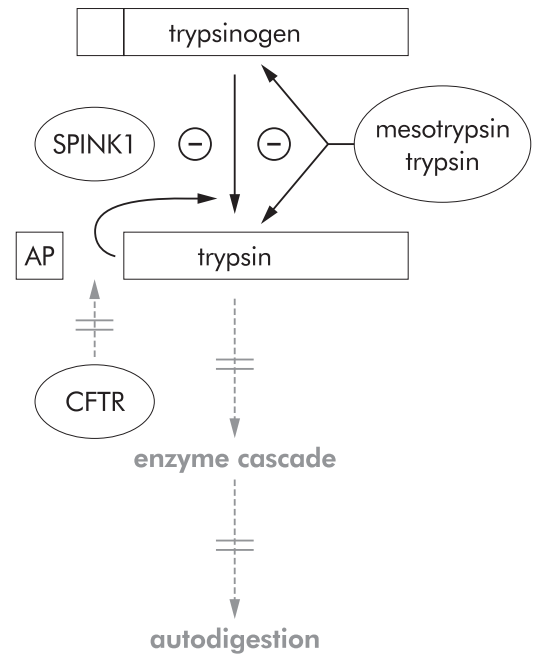

B

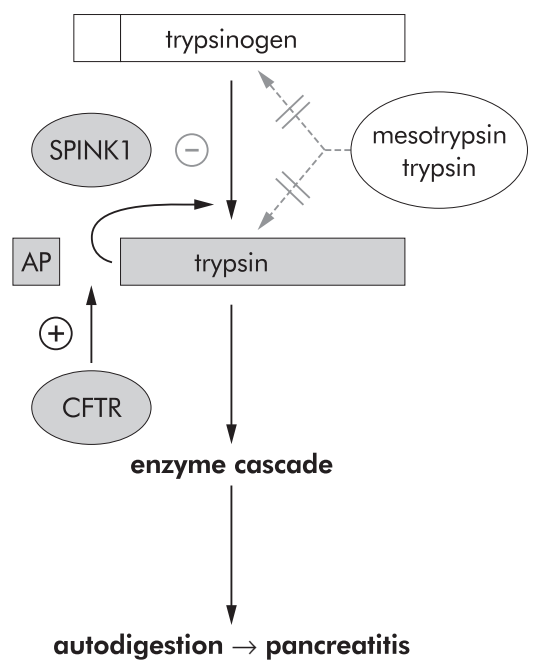

Figure 1 Model of inherited pancreatitis. (A) Condition in the normal pancreas: trypsin resulting from autoactivation of trypsinogen within the pancreatic parenchyma is inhibited by SPINK I and in the second line by mesotrypsin or trypsin This defence mechanism prevents the pancreas from activation of the pancreatic enzyme cascade and autodigestion. (B) Condition in inherited pancreatitis: mutations in PRSS 1 or in SPINK 1 lead to an imbalance of proteases and their inhibitors within the pancreatic parenchyma resulting in an inappropriate conversion of pancreatic zymogens to active enzymes with autodigestion and inflammation. Mutations in CFTR may disturb this delicate balance by intrapancreatic acidification or by a defective apical trafficking of zymogen granules and thus facilitate the intrapancreatic activation of digestive enzymes. Dark boxes represent products of mutated genes (modified from reference 34). (AP, activation peptide). found in patients without a family history of CP, indicating that PRSS1 mutations do not follow exclusively an autosomal dominant inheritance pattern. ${ }^{16}$ Thus, trypsinogen mutations display a considerable variability of penetrance.

There are different points of view about the significance of SPINK1 mutations in CP and the inheritance pattern. ${ }^{35}{ }^{63}$ In our opinion, different SPINKI mutations may lead to different inheritance patterns. For example, MIT mutation destroys the start codon resulting most probably in a "null" allele. The reported MIT family suggests a dominant inheritance. ${ }^{34} \mathrm{On}$ the other hand, N34S may decrease the SPINK1 capacity less resulting in recessive or complex trait. About $0.5 \%$ to $2 \%$ of the general population in Europe are N34S carriers and most will not develop CP. One may speculate that only the combination of N34S with other genetic defects or environmental factors results in CP. On the other hand, it is noteworthy that in two large studies about $5 \%$ to $10 \%$ of $\mathrm{CP}$ patients were homozygous for N34S. ${ }^{34}{ }^{35}$ According to an expected homozygote frequency of 1:10 000 to 1:40 000 in a general population, these data represent a striking enrichment of N34S homozygotes in $\mathrm{CP}$ patients and indicate a very strong influence of N34S on the disease pathogenesis.

We may classify SPINKI and PRSSI mutations into severe or mild with respect to the different degree in which this mutation affects protein function. Severe PRSSI mutations that result in a high disease penetrance such as $\mathrm{Rl} 22 \mathrm{H}$ may strongly facilitate autoactivation or may exhibit additional features such as trypsin stabilisation. Other PRSS1 mutations, such as Al6V, may facilitate autoactivation less and the disease initiating threshold is only reached in combination with other genetic or environmental factors. Also the effect of SPINK1 mutations may depend on the rate of pancreatic SPINKl reduction. In the heterozygous state, N34S may cause only a subliminal lowering of SPINKl, but initiate pancreatitis in the homozygous state.

Although an association between CFTR mutations and idiopathic CP is now well established, the pathogenic mechanisms are poorly understood. It may be speculated that the combination of two mild or of one mild and a severe CFTR mutation predisposes to CP. However, many patients with idiopathic show only one mutant CFTR allele. ${ }^{43} 52$ Possibly, CP is predisposed by compound heterozygosity for CFTR mutations or by a combination of defects in CFTR and other genes such as SPINKI as recently described. ${ }^{43}{ }^{52}$

\section{Disease model of inherited pancreatitis}

Several mechanisms protect the pancreas from autodigestion by activation of the pancreatic digestive cascade ${ }^{64}$ : intrapancreatic tryptic activity is prevented by the synthesis of digestive enzymes as inactive proenzymes (zymogens), by the localisation of the activating enzyme enteropeptidase outside the pancreas, and by a low calcium concentration. In the normal pancreas, small amounts of trypsinogen are hydrolysed to active trypsin in the pancreatic parenchyma, but this tryptic activity is dammed by co-synthesised protease inhibitors such as SPINK $1 .{ }^{65}$ Furthermore, trypsin itself activates trypsin-like enzymes such as mesotrypsin readily degrading trypsinogen and other zymogens ${ }^{66}$ (fig 1A). Pancreatitis may result from an imbalance of proteases and their inhibitors within the pancreatic parenchyma (fig 1B). Gain of function mutations in the cationic trypsinogen resulting in an increased autoactivation of the enzyme or loss of function mutations in SPINK1 resulting in a decreased inhibitory capacity may, in a similar way, disturb the delicate intrapancreatic balance of proteases and their specific inhibitors. The net effect of a single mutation may depend on the different degree in which this mutation affects protein function and on the presence of mutations in other genes such as CFTR. It has been suggested that pancreatic dysfunction in $\mathrm{CF}$ is a result of a decreased ductal $\mathrm{pH}^{67}$ This lowering of $\mathrm{pH}$ may subsequently lead to a defective solubilisation of proteins, a defective apical trafficking of zymogen granules, or to an increased autoactivation of trypsinogen. A slight reduction of CFTR function, as proposed for the heterozygous state, may raise the susceptibility for CP by facilitating the intrapancreatic activation of digestive enzymes.

The predominant feature of inherited pancreatitis is a relapsing pancreatitis. This clinical course poses the question why inherited pancreatitis is characterised by recurring instead of continuing inflammation, although the underlying genetic defect is present within the pancreatic parenchyma from the cradle to the grave. We postulate that endogenous or exogenous factors might trigger the particular event. Hereditary pancreatitis patients occasionally report that viral infections preceded the acute pancreatitis attack, suggesting that viral agents or drugs used for treatment such as salicylates initiate the acute event. In some of our patients the cause of pancreatitis was attributed to mild abdominal trauma 


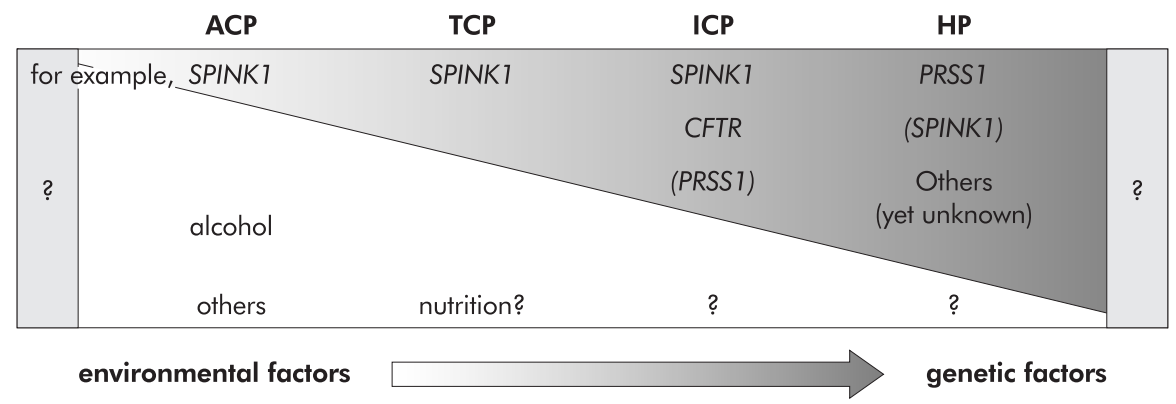

Figure 2 Schematic presentation of the influence of different genetic and environmental factors on the pathogenesis of chronic pancreatitis. $\mathrm{ACP}$, alcoholic chronic pancreatitis; TCP, tropical calcific pancreatitis; $\mathrm{ICP}$, idiopathic pancreatitis; $\mathrm{HP}$, hereditary pancreatitis. before genetic testing revealed a pathogenic PRSSI mutation (unpublished data).

\section{Alcohol related chronic pancreatitis}

The association between alcohol misuse and CP is well established. There is a wide variation between people in their susceptibility to alcohol and only $5 \%-10 \%$ of heavy drinkers develop CP. ${ }^{68}$ The role of genetic factors in the development of alcoholic CP is mostly unknown.

Several studies investigating PRSS $1,{ }^{69}$ pancreatitis associated protein $(\mathrm{PAP}),^{70} \alpha_{1}$ antitrypsin, CFTR, ${ }^{44}{ }^{71}$ alcohol dehydrogenase and MHC antigens ${ }^{72}$ gave negative or conflicting results. Recently, an association between the SPINK1 N34S mutation and alcoholic CP in a large cohort of patients originating from three different countries has been described: a heterozygous N34S mutation was detected in 16 of 274 patients with alcoholic CP $(5.8 \%)$, but in only 4 of 540 healthy control individuals $(0.8 \%)$ and in 1 of 98 alcoholic controls without CP $(1.0 \%) .^{73}$ Two subsequent studies observed also an N34S frequency in alcohol related $\mathrm{CP}$ of $6.0 \%$ and $5.6 \%$ respectively. ${ }^{37}{ }^{38}$ However, one study failed to find a significant association between N34S and alcoholic CP because of the high N34S frequency in their control subjects (4 of 100). ${ }^{38}$

Analysis of pancreatic juice showed an increase of the trypsinogen/trypsin inhibitor ratio in alcoholics compared with non-alcoholic controls, indicating a weakening of the defence mechanism provided by the trypsin inhibitor against premature zymogen activation. ${ }^{74}$ As most alcoholics do not suffer from CP, the association between SPINKl mutations and alcoholic CP underlines the relevance of the pancreatic protease/protease inhibitor system in the disease pathogenesis and supports the hypothesis that a combination of exogenous and genetic factors may predispose to alcoholic CP.

\section{Indications for genetic analysis}

Testing for PRSSI and SPINKI mutations is indicated in all patients with acute or chronic pancreatitis and a family history of CP or pancreatic cancer as well as in all patients with chronic CP without a family history after exclusion of predisposing factors such as alcohol misuse or hypertriglyceridaemia. In the presence of a family history, genetic testing should be started with analysis for the PRSSI mutations $\mathrm{R} 122 \mathrm{H}$ or N29I, which will be most probably found in these cases, whereas in the absence of family history most probably a SPINK1 N34S mutation, a PRSS1 Al6V mutation, or a CFTR mutation will be identified. So far, only limited data are given about the occurrence of PRSSI or SPINKI mutations in patients with secondary $\mathrm{CP}$ - that is, alcohol misuse, anatomical anomalies, etc. Future studies will clarify if clinical testing is appropriate in these patients. A negative genetic test result does not exclude a genetic basis of the disease: in our study population more than $50 \%$ of patients with primary CP do not show a mutation in one of the two above mentioned genes. As genetic analyses are expensive and time consuming, genetic testing should not be performed in patients with acute pancreatitis without a family history of CP. Because of the lack of therapeutic consequences, asymptomatic relatives should be screened after detailed counselling only. As patients with CF may suffer from recurrent attacks of pancreatitis without significant pulmonary disease or malabsorption, all patients with raised or borderline sweat chloride concentrations should be tested for CFTR mutations. In our opinion, prenatal testing for PRSSI or SPINKI mutations is not indicated.

\section{Rethinking chronic pancreatitis}

The genetic studies about inherited pancreatitis have substantially changed our disease understanding. For a long time, hereditary pancreatitis was thought to be a rare disorder. The recent findings of PRSSI, SPINKI, and CFTR mutations in patients with so called idiopathic $\mathrm{CP}$, however, demonstrate that inherited cases of $\mathrm{CP}$ are much more common than originally envisioned. These data challenge the differentiation between "hereditary" and "idiopathic" pancreatitis. Different mutations in different genes might lead to different phenotypic presentations and inheritance pattern and even the same mutation in the same gene might have different consequences depending on the individual's genetic background and environmental factors. The discovery of SPINK1 mutations in other types of CP such as tropical calcific pancreatitis (unpublished data) and alcohol induced CP further blur the borders between the particular CP subtypes. Future research will most probably reveal a very complex interaction between various environmental and genetic factors with flowing transitions among these subtypes (fig 2). This hypothesis is supported by the observation of SPINK1 mutations in individuals in which the cause of $\mathrm{CP}$ was attributed to metabolic disorders or anatomical anomalies. ${ }^{37}$

In several symposiums held in Marseilles, Cambridge, and Rome, experts tried to define and to classify inflammatory pancreatic diseases. According to these classification systems, $\mathrm{CP}$ is currently defined as an continuing inflammatory disease characterised by the destruction of pancreatic parenchyma leading to progressive or permanent impairment of exocrine function, endocrine function, or both. ${ }^{375}{ }^{76}$ It is important to note that these classifications scarcely consider aetiological factors. According to this classification, acute pancreatitis has been defined "not as a disease but as a spectrum of inflammatory lesions" ${ }^{76}$ Furthermore, most participants agreed that CP is a cause and not a consequence of acute pancreatitis and that acute pancreatitis only rarely progresses to $\mathrm{CP}^{3}{ }^{77}$ According to this concept, acute and chronic pancreatitis are two separate diseases that rarely merge.

The current definition of chronic pancreatitis, however, is not compatible with the presentation of inherited pancreatitis. The predominant feature of inherited pancreatitis is a relapsing pancreatitis starting in childhood with initially absent signs of functional or morphological pancreatic damage. During the course of the disease, most of the patients with acute relapsing pancreatitis develop all morphological and functional signs of CP. Consequently, acute and chronic pancreatitis have to be considered as different stages of one dynamic disease process. The different concepts of $\mathrm{CP}$ in the paediatric and non-paediatric literature reflect the fact that the paediatrician is confronted with the early stage of disease, 
whereas the internist is usually dealing with its late stage. The findings of the same genetic defects in different types of acute and chronic pancreatitis support the old concept that all intermediate stages between acute pancreatitis and chronic calcifying pancreatitis may exist as pristinely postulated by Comfort and coworkers. ${ }^{78}$

\section{Summary}

Since the first description of inherited pancreatitis reported an autosomal dominant trait, hereditary $\mathrm{CP}$ was defined as an rare dominant inherited disease. Subsequently, the fact of familial clustering in one generation only, which indicates other inheritance pattern such as recessive or complex trait, was blinded out in the disease concept of hereditary CP for a long time. The identification of PRSS1, SPINK1, and CFTR mutations in patients with so called idiopathic chronic pancreatitis, however, shows that inherited cases of CP are much more frequent and that different mutations in different genes might lead to different inheritance pattern. Evaluation of patients with $\mathrm{CP}$ without an obvious predisposing factor should include genetic testing for mutations in the above mentioned genes even in the absence of a family history of pancreatitis. The finding of SPINKI mutations in alcohol induced pancreatitis indicates that genetic factors may increase disease susceptibility to primary non-hereditary CP types. Thus, the identification of further genes involved into the pathogenesis of inherited CP probably will also improve our knowledge about more common types of CP such as alcoholic or tropical CP.

\section{CYSTIC FIBROSIS}

CF is an autosomal recessive inherited disorder characterised by chronic obstructive pulmonary disease with proximal bronchiectasis often resulting in lung failure, by exocrine pancreatic insufficiency with maldigestion, and by increased sweat chloride concentration. Other clinical features include meconium ileus, liver fibrosis, and male infertility due to obstructive azoospermia. The incidence of CF in the white population is about $1: 2500$. The present review focuses mainly on the CFTR genotype phenotype correlation with respect to disease involvement of different organs, the impact of genetic modifying factors on the phenotype, and the impact of CFTR changes on diseases other than CF.
In 1989, CFTR was identified as the CF gene by linkage analysis and chromosome walking (positional cloning). ${ }^{790}$ Human CFTR is located on the long arm of chromosome 7 (7q31), spans about $250 \mathrm{~kb}$, and is separated into 27 exons. ${ }^{80} 81$ CFTR belongs to the ATP binding cassette (ABC) superfamily and encodes a transmembrane protein present at the surface of most epithelial cells functioning as a cyclic adenosine monophosphate (cAMP) responsive chloride channel. ${ }^{82}$ CFTR has also been implicated in several other processes such as regulation of other ion channels and membrane trafficking. CFTR comprises two membrane spanning domains (MSD1 and MSD2), two nucleotide binding domains (NBD1 and NBD2), and a central, intracellulary regulatory domain ( $\mathrm{R}$ region) with multiple phosphorylation sites. ${ }^{79} 83$

So far, more than 1000 CFTR mutations have been identified. The most common CFTR mutation is a deletion of three nucleotides in exon 10 abolishing a phenylalanine residue at position 508 (F508del). Worldwide, this mutation accounts for $66 \%$ of all CF chromosomes. ${ }^{84}$ About $50 \%$ of CF patients are homozygous for this mutation. The impact of a specific CFTR mutation on the disease severity depends on various factors such as type of mutation (missense, frameshift deletion, etc), the consequences of the mutation for structure and function (mutation class) and the position of mutation within the gene (location in functionally or structurally relevant regions). Also, the presence of other genetic alterations within the same allele can significantly influence the phenotypic effect as in the case of the R117H mutation. ${ }^{51}$

CFTR mutations can be divided into five or six general classes that reflect their known or predicted molecular dysfunction $^{85-87}$ (fig 3). Mutations resulting in defective transcription of mRNA (class I) lead to virtually no functional protein and are equivalent to a "null" mutation. Class II mutations are characterised by defect processing or trafficking of the CFTR protein. To this class belongs the most common CFTR mutation, F508del, which leads to degradation of the protein in the endoplasmic reticulum. ${ }^{88}$ Mutations leading to a defective activation (class III) because of alteration of ATP binding or hydrolysis at the nucleotide binding domains (NBD) result in a normal but non-functional amount of CFTR protein at the cell membrane. Class IV mutations such R117H and R347P affect the chloride conductive function and are associated with decreased but residual CFTR function. Class V
Class VI

defective regulation of other ion channels (del508, G551D)

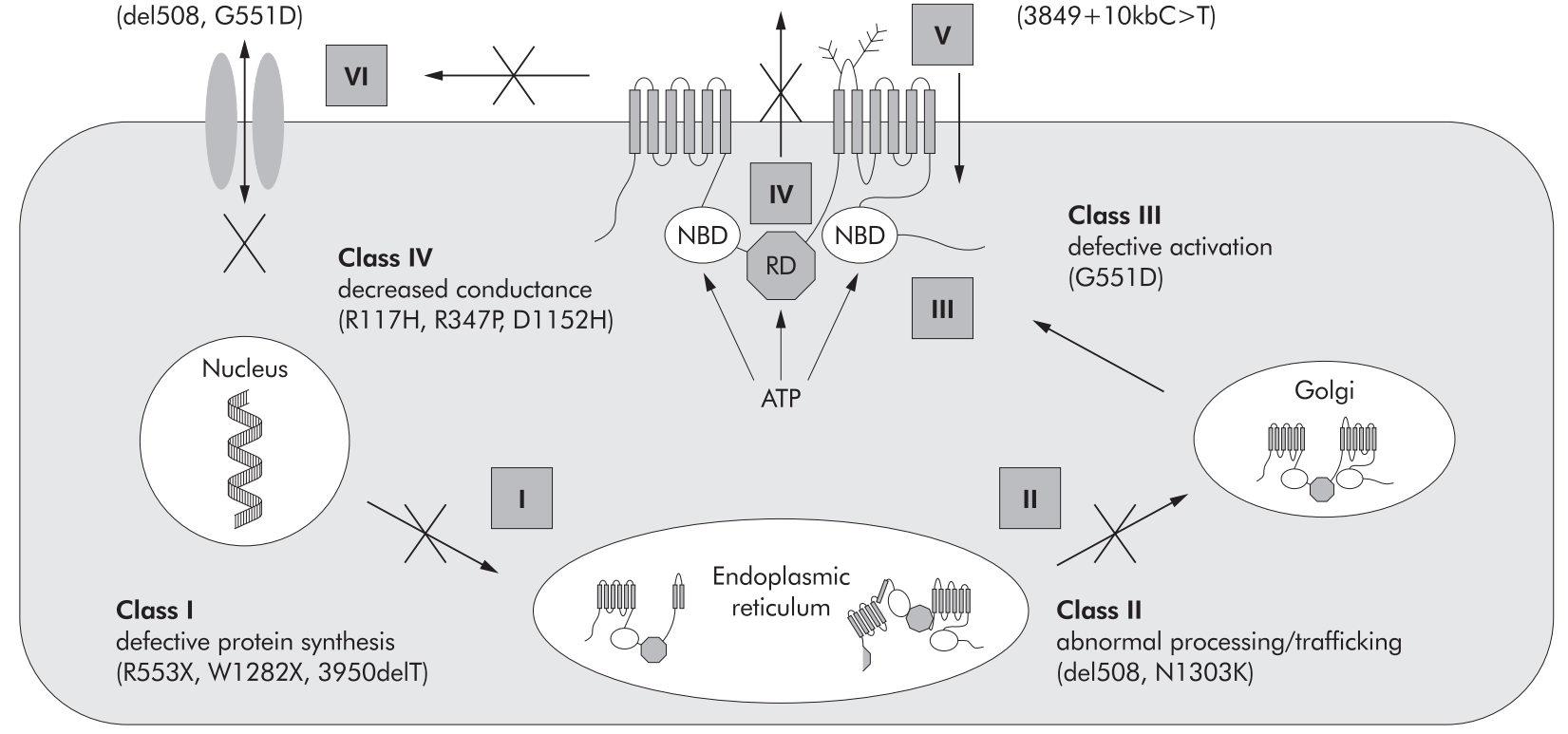

Class V

reduced synthesis

$(3849+10 \mathrm{kbC}>\mathrm{T})$

Figure 3 CFTR mutations classes. The subdivision reflects the known or predicted biosynthetic and functional consequences. 
mutations result in a decreased amount of functional protein by abnormal splicing or reduced trafficking. Some mutations may also affect the regulatory function of CFTR on other ion channels (class VI). Class I-III mutations generally affects the amount of functional CFTR more seriously than class IV and V mutations and are usually associated with a classic CF. It is worthwhile to note that a specific mutation can be associated with more than one of the above mentioned mechanisms: the G551D mutation affects activation (class III) as well as the regulatory property of CFTR on other ion channels ("class $\left.\mathrm{VI}^{\prime \prime}\right) .{ }^{89}$

\section{Genotype phenotype correlation and modifier genes}

The course of disease differs between individuals with identical CFTR mutations even in the same family suggesting that environmental and inherited factors may modify the disease phenotype. Pancreatic function is strongly determined by the CFTR genotype, whereas the course of pulmonary disease seems to be largely dependent on secondary factors.

\section{Pancreas}

Pancreatic damage in CF is characterised by widespread loss of acinar cells with fatty replacement and interstitial fibrosis. Pancreatic disease in CF varies from complete loss of exocrine and endocrine function to nearly normal pancreatic function. About $90 \%$ of the CF patients show exocrine pancreatic insufficiency. The type respectively class of CFTR mutation correlates closely with the pancreatic function: the vast majority of patients homozygous for F508del are pancreatic insufficient. However, a small percentage of F508del homozygotes has preserved pancreatic function. ${ }^{91}$

\section{Liver}

Chronic fibrotic liver disease accounts for virtually all non-pulmonary causes of mortality in patients with CF. Histopathologically, CF related liver disease is characterised by focal biliary fibrosis. Clinically significant liver disease develops in $2 \%-5 \%$ of the patients.

Several studies failed to find any significant association between a specific CFTR mutation or mutation class and the development of liver disease. ${ }^{91-94}$ Colombo and coworkers analysed 189 CF patients for clinical and genetic risk factors of liver disease and did not find any genotype phenotype correlation. However, the risk of acquiring liver disease was increased about fourfold in patients with a history of meconium ileus or distal intestinal obstruction syndrome (DIOS) in comparison with CF patients unaffected by these complications. ${ }^{93}$ Others investigated $288 \mathrm{CF}$ patients and found no difference in the CFTR genotype distribution or a history of meconium ileus or DIOS in patients with and without liver disease. ${ }^{94}$ In both studies, pancreatic insufficiency was present in all patients with liver disease. However, liver fibrosis has also been reported in patients with pancreatic sufficiency. ${ }^{95}$

Only two studies investigated the role of genetic modifying factors in CF related liver disease. Duthie and coworkers analysed major histocompatibility complex (MHC) genes and found a significant difference of the DQ6 allele in patients with liver disease compared with those without liver disease or healthy controls. ${ }^{96}$ Another group found a significant association of mannose binding lectin (MBL2) (for MBL2 see paragraph pulmonary disease) deficiency and liver cirrhosis in 216 F508del homozygous CF patients: 5.4\% with wild type or one mutated MBL2 allele showed evidence of cirrhosis compared with $30.8 \%$ of those patients with two deficiency alleles. ${ }^{97}$ So far, the relation between liver disease and genetic variations of MHC genes or MBL2 has not been investigated by other groups and remains to be confirmed.

\section{Meconium ileus}

About $10 \%$ to $20 \%$ of neonates with CF will present with meconium ileus, an intestinal obstruction attributable to inspissation of meconium in the terminal ileum..$^{98}$ Almost all patients with meconium ileus have pancreatic insufficiency. Meconium ileus seems to be independent from the type or class of the underlying CFTR mutation. ${ }^{90} 100$ Kerem and coworkers observed a recurrence rate of meconium ileus in $29 \%$ of subsequent siblings in families in which the first child had meconium ileus compared with $6 \%$ of siblings born to families in which the first child did not have meconium ileus. ${ }^{99}$ Both, the poor genotype phenotype correlation and the familial clustering indicate that other genetic factors might be involved in the pathogenesis of neonatal intestinal obstruction. Recently, a CF modifier locus for meconium ileus on the long arm of the human chromosome 19 (19q13) has been identified. ${ }^{101}$ However, there was no single haplotype associated with meconium ileus suggesting multiple mutations in the modifier gene or multiple modifier loci. So far, the underlying genetic defect or defects have not been identified.

A candidate gene study investigated the role of haemochromatosis (HFE) gene mutations as modifier for meconium ileus in CF patients. ${ }^{102}$ The carrier frequency of the $\mathrm{C} 282 \mathrm{Y}$ mutation in the HFE gene among 89 F508del homozygotes was significantly higher in those with meconium ileus if compared with the unaffected controls (19.4\% versus $7.7 \%)$, but not if compared with CF patients without meconium ileus (19.4\% versus $10.3 \%) .{ }^{102}$ These findings remain to be confirmed in larger study populations.

\section{Pulmonary disease}

Pulmonary disease is the primary cause of death in CF and accounts for more than $90 \%$ of the mortality. It is proposed that abnormal electrolyte transport because of a defect CFTR causes altered mucus viscosity and decreased mucosal defence against infection, which lead to airway plugging, chronic inflammation, and progressive destruction of the lung.

CF patients demonstrate a high variability in pulmonary disease that poorly correlates with the type of CFTR mutation..$^{90} 10{ }^{104}$ This is in contrast with pancreatic involvement: pancreatic sufficiency is frequently associated with mild CFTR mutations. ${ }^{90}$ In the past years, polymorphisms in various candidate genes have been investigated by several groups.

MHC genes play an important part in immune defence and allergic reactions. MHC class II alleles have been implicated as possible modifiers of the pulmonary phenotype by influencing specific IgE levels and susceptibility to chronic Pseudomonas aeruginosa colonisation. ${ }^{105}$ Among CF patients, there was a higher probability of colonisation with Pseudomonas aeruginosa in those with the $D R 7$ allele, and a lower probability of colonisation in those with the DR4 allele. Twelve of 98 patients were not yet colonised with Pseudomonas aeruginosa: none of the 12 were $D R 7+$ and 6 were $D R 4+.^{105}$

Deficient $\alpha_{1}$ antitrypsin variants also have been associated with earlier onset of lung colonisation with Pseudomonas aeruginosa and higher total IgG levels. ${ }^{106}$ However, these findings could not be confirmed by others. Instead, Mahadeva and coworkers found a significantly better lung function in CF patients with an $\alpha_{1}$ antitrypsin deficiency allele. ${ }^{107} 108$

The same group also investigated $\alpha_{1}$ antichymotrypsin in 157 CF patients and found that patients with $\alpha_{1}$ antichymotrypsin deficiency have less, rather than more severe pulmonary disease. ${ }^{109}$ The authors hypothesised that a genetic deficiency of proteinase inhibitors might permit downregulation of the inflammatory response and thereby reducing the severity of pulmonary damage.

Tumour necrosis factor $\alpha(\mathrm{TNF} \alpha)$ is a potent immunomodulator and proinflammatory cytokine. TNF $\alpha$ polymorphisms have been implicated in the pathogenesis of various autoimmune and infectious diseases. A biallelic promoter polymorphism (-308 G>A) influences the level of TNF $\alpha$ transcription. ${ }^{110}$ Hull and Thomson investigated 53 CF patients and found a significant association between the high expression $\mathrm{TNF} \alpha$ allele (TNF2, -308 A) and reduced pulmonary 
function as determined by $\mathrm{FEV}_{1}{ }^{111}$ The TNF $\alpha$ gene is located between the MHC class I and MHC class II loci. Thus, the observed association may be attributable to linkage disequilibrium between the TNF2 allele and MHC alleles.

Transforming growth factor $\beta_{1}\left(\mathrm{TGF} \beta_{1}\right)$ is a multifunctional cytokine that promotes fibroblast proliferation and collagen deposition. ${ }^{112}$ TGF $\beta_{1}$ production shows an interindividual variability that partly depends on polymorphisms in the promoter and in the signal peptide region. Arkwright and coworkers studied 171 CFTR F508del homozygotes for the TGF $\beta_{1}$ L10P and R25P polymorphisms and found an accelerated decline of pulmonary function in patients with a leucine allele than in those with a proline allele at codon 10 . The authors implied that a high TGF $\beta_{1}$ producer genotype predisposes CF patients to more rapidly development of pulmonary disease. ${ }^{113}$ However, no association with the codon 25 allele, which is known to influence TGF $\beta_{1}$ production, ${ }^{114}$ was found, and no data exist about the impact of the LIOP polymorphism on TGF $\beta_{1}$ synthesis.

Glutathione S transferase Ml (GSTMI) belongs to a multigene family of enzymes involved in detoxification and cellular protection against oxidative stress by removal of reactive oxygen species and regeneration of $S$-thiolated proteins. Three GSTMI alleles have been identified: GSTMI*A, GSTMI ${ }^{*} B$, and $G S T M 1 * 0$. Some $40 \%$ to $65 \%$ of the human population are homozygous for a deletion of the entire gene $\left(\text { GSTM1 }{ }^{*} 0\right)^{115}$ and thus do not produce the protein. The GSTMI ${ }^{*} 0$ allele has been associated with an increased risk for various cancers. ${ }^{116}{ }^{117}$ Baranov and coworkers investigated 194 CF patients for the GSTMI ${ }^{*} 0$ allele and reported a significant association between homozygosity for the null genotype and earlier diagnosis of CF. ${ }^{118}$ However, no data about pulmonary function or Pseudomonas aeruginosa colonisation have been given. In a subsequent study, a lower Shwachman score and a higher Chrispin-Norman chest radiographic score in patients with the null allele have been found. ${ }^{111}$ However, the number of investigated patients was small and no differences of FEV were observed between homozygous and non-homozygous patients. Both studies implied that the observed associations might be attributable to the reduced ability to deal with oxidant stress, particularly within the lung. It might be worthwhile to note that GSTMI is expressed at high levels in the liver but is only weakly synthesised in lung tissue. ${ }^{119}$

Nitric oxide (NO) is an important factor in cell signalling, pathogen killing, and smooth muscle relaxation. NO is synthesised by a group of enzymes called NO synthases (NOS). As NO is important in bactericidal action, lowered levels of NO might lead to an increased risk of infection. Exhaled NO levels are reduced in $\mathrm{CF}^{120}$ One group investigated the size of an AAT trinucleotide repeat in intron 20 of the NOS1 gene in CF patients. ${ }^{121}$ Although no differences between FEV, and FVC were observed in patients with different trinucleotide sizes, expired NO was significantly lower in patients who harboured two alleles with a high number of repeats $(>12)$ than in those who showed alleles with fewer repeats. Moreover, colonisation with Pseudomonas aeruginosa and Aspergillus fumigatus was significantly more common in patients with high repeat numbers. ${ }^{121}$ The authors supposed that lowered NO formation attributable to high repeat numbers in NOSI might render CF patients more susceptibly to airway colonisation.

More recently, mutations in the gene encoding for mannose binding lectin 2 (MBL2) have been associated with the severity of lung disease and mortality in patients with CF. ${ }^{122} 123 \mathrm{MBL}$ is a serum protein that belongs to the collectin subgroup of the C type lectin superfamily. ${ }^{124}$ Collectins bind specifically to oligosaccharides on the surface of microbial pathogens, thereby initiating agglutination, neutralising or opsonisation of the micro-organisms for phagocytosis. It has been shown that MBL2 alleles causing low MBL serum concentrations are associated with an increased risk of different types of infections. ${ }^{125-128}$ Three missense mutations in the exon 1 of
MBL2 independently cause low MBL serum concentrations: Gly 54 Asp (G54D), Gly 57 Glu (G57E), and Arg 52 Cys (R52C). ${ }^{125} 129130$ Several nucleotide substitutions in the promoter region may also affect the MBL serum level. ${ }^{131}{ }^{132}$ Garred and coworkers analysed 149 CF patients for MBL2 mutations and found a significant reduction of pulmonary function ( $F E V$, and FVC) in patients carrying a variant MBL2 allele. Moreover, death and lung transplantation were increased threefold in patients with variant MBL. ${ }^{122}$ Gabolde and colleagues compared the clinical characteristics of 11 patients homozygous or compound heterozygous for MBL2 mutations with 11 sex and age matched CF patients with wild type $M B L 2$ and also found a significant decrease of pulmonary function in those with mutant MBL2. ${ }^{123}$

We have to point out that most of reported pulmonary modifiers in CF were analysed by one group only and remain to be confirmed in future studies. Because spurious results in genetic association studies are common, the obtained data should be interpreted warily. As yet, the association between $M B L 2$ deficiency alleles and decreased lung function only have been reported by two independent groups. However, MBL2 mutations explain only a small part of clinical variability. Therefore, other genetic variations probably contribute to the disease course and the host susceptibility to colonisation with Pseudomonas aeruginosa and other pathogens. The detection of further pulmonary modifier genes in the near future is probable and will have an important impact on new therapeutic strategies by influencing the identified proteins or their pathways.

\section{CFTR mutations in other diseases than CF}

Mutations in the CFTR gene not only cause CF but also have been associated with other diseases such as idiopathic chronic pancreatitis (see paragraph chronic pancreatitis above), male infertility due to congenital bilateral absence of the vas deferens (CBAVD), disseminated bronchiectasis, allergic bronchopulmonary aspergillosis (ABPA), asthma, chronic rhinosinusitis, and sarcoidosis.

\section{Congenital bilateral absence of the vas deferens (CBAVD)}

It is common knowledge that most men with CF are infertile because of obstructive azoospermia. Histological studies have demonstrated absence of the vas deferens and a rudimentary or absent epididymis. ${ }^{133}$ CBAVD occurs in $1 \%-2 \%$ of the infertile male population. Dumur and colleagues described an increased frequency of F508del heterozygotes in a group of 17 CBAVD patients. ${ }^{134}$ The increased frequency of CFTR mutations has been confirmed by many others. ${ }^{135-140}$ About $60 \%$ to $70 \%$ of CBAVD patients show at least one known CFTR mutation. It has been hypothesised that CFTR mutations cause defective chloride transport in the epididymis and possible early regression of the mesonephric duct.

In contrast with classic $\mathrm{CF}$, patients with CBAVD predominantly exhibit "mild" CFTR mutations (class IV or V) with residual functional CFTR. One characteristic of CBAVD is the high frequency of the $5 T$ allele, which is present in $40 \%$ to $50 \%$ of the patients. ${ }^{139}{ }^{140}$ Three length variants of a polypyrimidine tract within the splice acceptor site in intron 8 of the CFTR gene have been found to be associated with varying degrees of exon 9 splicing. ${ }^{141}{ }^{142}$ Of the three alleles with variable numbers of thymidines (5T, $7 \mathrm{~T}$, or 9T), the $9 \mathrm{~T}$ allele is associated with more efficient normal splicing of exon 9, whereas the $5 T$ allele leads to inefficient splicing with skipping of exon 9 and a defective chloride channel function. ${ }^{143}$ The $5 T$ allele can also modify the phenotypic effect of other mutations. For instance, the R117H mutation in exon 4 of the CFTR gene may be located in cis (on the same chromosome) with 5T. The R117H mutation on the $5 T$ background shows a cumulative effect and is associated with pulmonary disease in $\mathrm{CF}$, whereas $\mathrm{R} 117 \mathrm{H}$ 
combined with the more common $7 T$ allele is typically observed in CBAVD without lung disease. ${ }^{51}$

\section{Disseminated bronchiectasis}

Poller and coworkers described an increased frequency for the F508del mutation in patients with disseminated bronchiectasis. ${ }^{144}$ Subsequent studies confirmed the association between CFTR variants and disseminated bronchiectasis. ${ }^{145-149}$ Pignatti and coworkers found a CFTR mutation or rare variant in $37.5 \%{ }^{145}$ and the $5 \mathrm{~T}$ allele in $31 \%$ of bronchiectasis patients. ${ }^{146}$ Several CFTR variants were also detected in French patients with idiopathic bronchiectasis, however, the $5 T$ allele was not detected in any patient. ${ }^{147}$ Other studies described a CFTR mutation in 5 of 16 patients $(22 \%)$ respectively in 5 of 19 patients $(26 \%))^{148} 149$

\section{Asthma}

Conflicting data exist about the influence of CFTR mutations on the risk of asthma. In one study a protective effect of F508del against asthma was observed, ${ }^{150}$ but could not confirmed by others. ${ }^{151}$ In a questionnaire survey, Dahl and coworkers reported asthma in 23 of 150 F508del heterozygotes (9\%) compared with 529 of 8891 non-carriers (6\%). Among the individuals with asthma $4.2 \%$ were F508del carriers compared with $2.7 \%$ of individuals without asthma. ${ }^{152}$ A Spanish study detected in 21 of 144 asthma patients (15\%) a CFTR missense mutation. ${ }^{153}$ The distribution of $\mathrm{FEV}_{1} / \mathrm{FVC}$ ratio and the predicted FEV \% were similar in people with asthma with and without a CFTR variation. ${ }^{153}$ However, investigating the four more common CFTR alterations found in asthmatics in an extended control sample, no significant difference was observed. Moreover, two of the CFTR mutations found were previously reported as non-disease causing polymorphisms (R1162L, T1220I), five alterations were described for the first time and have not been demonstrated in a previous study of 640 Spanish CF patients. ${ }^{154}$ In summary, only 4 of 144 asthmatic patients $(2.8 \%)$ possessed a verified CF causing mutation (R74W, I148T, T582R, and R1066C). A French group did not detect a statistically significant difference of CFTR variations between patients with asthma and controls: two of 43 patients (4.6\%) and 6 of 142 control subjects (4.2\%) were heterozygous for a CFTR mutation. ${ }^{155}$ In another study, a group of 261 obligate CFTR heterozygotes and a control group, composed of 201 people negative for a standard mutation panel, were surveyed for possibly CF related conditions by a questionnaire. There was no difference between heterozygotes and controls for asthma, bronchiectasis, pneumothorax, allergic bronchopulmonary aspergillosis, sinusitis, and nasal polyps. ${ }^{156}$

\section{Allergic bronchopulmonary aspergillosis (ABPA)}

ABPA, a hypersensitivity disorder caused by chronic endobronchial infection with Aspergillus fumigatus, was first described in asthmatic patients. ${ }^{157}$ In subjects with impaired mucus clearance and airway obstruction, the spores may germinate and release an array of antigens, resulting in a complex immune response by the host. ABPA is also a complication of CF observed in $2 \%$ to $8 \%$ of patients. ${ }^{158}{ }^{159}$ Familial occurrence of ABPA has been reported, suggesting a genetic contribution to the disease. ${ }^{1601} 161$ Miller and coworker investigated 11 patients with isolated ABPA and normal sweat electrolytes for CFTR mutations and detected in six patients at least one mutation. ${ }^{162}$ Others found a heterozygous CFTR mutation in 6 of 21 ABPA patients (28.5\%). ${ }^{155}$

\section{Chronic sinusitis}

CF patients commonly suffer from chronic sinusitis. Wang and coworkers analysed 147 patients with isolated chronic sinusitis and 123 controls for CFTR mutations and found a significant difference between both groups: eleven patients
(7\%) showed at least one CFTR mutation, whereas two control subjects (2\%) only were CFTR heterozygotes. ${ }^{163}$ Another group investigated 58 children with chronic rhinosinusitis and detected in seven patients (12.1\%) a CFTR mutation. Only one of the seven children showed a borderline abnormal sweat test. Two of the 58 patients experienced recurrent Pseudomonas aeruginosa sinusitis, and both were F508del heterozygotes. ${ }^{164} \mathrm{In}$ both studies, the frequency of the $5 T$ allele in the patient group was similar to that in the control group respectively to that reported for the general population. ${ }^{163}{ }^{164}$ In contrast, a Finnish study investigated 127 chronic sinusitis patients for the F508del and 394delTT mutations representing 75\% of the CF chromosomes in Finland, and found only one CFTR heterozygote. ${ }^{165}$

\section{Sarcoidosis}

Recently, Bombieri and coworkers observed a significantly increased frequency of CFTR mutations in patients with sarcoidosis. ${ }^{166}$ The authors detected in 8 of 26 patients a CFTR variation, but only in 9 of 89 control subjects. There was also a trend towards disease progression in patients with a CFTR mutations compared with patients without a mutation. However, some of the reported CFTR alterations have been found frequently in healthy individuals such as R75Q or L997F and might represent polymorphisms. Further studies are needed to elucidate the role of CFTR mutations in the predisposition to sarcoidosis.

\section{Summary}

The course of CF shows differences between patients even with the same CFTR mutation, suggesting that environmental and inherited factors modify the phenotype. Pancreatic function is strongly determined by the CFTR genotype, whereas the course of liver fibrosis and especially of pulmonary disease seem to be largely dependent on secondary factors. Thus, the phenotype is set by CFTR mutations as well as by the individual genetic background and environmental factors and varies between different organs depending on the specific organ susceptibility for defect CFTR. The identified association of MBL2 mutations with the severity of pulmonary disease and mortality in CF patients is a first clue in understanding how genetic alterations do modify the pulmonary phenotype. The identification of further disease modifying genetic factors will contribute to our pathophysiological understanding and may open new ways of therapeutic strategies in the future. The increased frequency of CFTR mutations in diseases other than CF such as CBAVD or idiopathic pancreatitis contributes to the understanding of these entities, but also gives difficulties in nosological demarcations between $\mathrm{CF}$ and these disorders and indicates a smooth passage between CF and CFTR related diseases.

\section{REFERENCES}

1 Ammann RW, Bühler $\mathrm{H}$, Münch R, et al. Differences of the natural history of idiopathic (nonalcoholic) and alcoholic chronic pancreatitis. A comparative long-term study of 287 patients. Pancreas 1987;2:368-77.

2 Durbec JP, Sarles H. Multicenter survey on the etiology of pancreatic diseases. Relationship between the relative risk of developing chronic pancreatitis and alcohol, protein, and lipid consumption. Digestion 1978; 18:337-50

3 Singer MV, Gyr K, Sarles H. Revised classification of pancreatitis. Report of the Second International Symposium on the Classification of Pancreatitis in Marseille, France, March 28-30, 1984. Gastroenterology 1985;89:683-5

4 Comfort MW, Steinberg AG. Pedigree of a family with hereditary chronic relapsing pancreatitis. Gastroenterology 1952;21:54-63.

5 Chiari $\mathbf{H}$. Über Selbstverdauung des menschlichen Pankreas. Zeitschrift für Heilkunde 1896;17:69-96

6 Steer ML, Meldolesi J. The cell biology of experimental pancreatitis. N Engl J Med 1987:316:144-50.

7 Scheele GA, Bartelt D, Bieger W. Characterization of human exocrine pancreatic proteins by two-dimensional isoelectric focusing/SDS gel elctrophoresis. Gastroenterology 1981;80:461-73.

8 Colomb E, Guy O, Deprez P, et al. The two human trypsinogens: catalytic properties of the corresponding trypsins. Biochim Biophys Acta 1978;525: 186-93. 
9 Colomb E, Figarella C. Comparative studies on the mechanism of activation of the two human trypsinogens. Biochim Biophys Acta 1979;571:343-51

10 Whitcomb DC, Preston RA, Aston CE, et al. A gene for hereditary pancreatitis maps to chromosome 7q35. Gastroenterology 1996; 110:1975-80.

11 Le Bodic L, Bignon JD, Raguénès $O$, et al. The hereditary pancreatitis gene maps to long arm of chromosome 7. Hum Mol Genet 1996;5:549-54.

12 Pandya A, Blanton SH, Landa B, et al. Linkage studies in a large kindred with hereditary pancreatitis confirms mapping of the gene to a 16-cM region on 7q. Genomics 1996;38:227-30

13 Whitcomb DC, Gorry MC, Preston RA, et al. Hereditary pancreatitis is caused by a mutation in the cationic trypsinogen gene. Nat Genet 1996;14:141-5.

14 Gorry MC, Gabbaizedeh D, Furey W, et al. Mutations in the cationic trypsinogen gene are associated with recurrent acute and chronic pancreatitis. Gastroenterology 1997;113:1063-8.

15 Teich N, Mössner J, Keim V. Mutations of the cationic trypsinogen in hereditary pancreatitis. Hum Mut 1998;12:39-43.

16 Witt $\mathbf{H}$, Luck $W$, Becker $M$. A signal peptide cleavage site mutation in the cationic trypsinogen gene is strongly associated with chronic pancreatitis. Gastroenterology 1999:117:7-10.

17 Férec $C$, Raguénès $O$, Salomon $R$, et al. Mutations in the cationic trypsinogen gene and evidence for genetic heterogeneity in hereditary pancreatitis. J Med Genet 1999;36:228-32.

18 Teich N, Ockenga J, Hoffmeister A, et al. Chronic pancreatitis associated with an activation peptide mutation that facilitates trypsin activation. Gastroenterology 2000;1 19:461-5.

19 Chen JM, Piepoli Bis A, Le Bodic L, et al. Mutational screening of the cationic trypsinogen gene in a large cohort of subjects with idiopathic chronic pancreatitis. Clin Genet 2001;59:189-93

20 Le Maréchal C, Bretagne JF, Raguénès $O$, et al. Identification of a novel pancreatitis-associated missense mutation, R 1 16C, in the human cationic trypsinogen gene (PRSS1). Mol Genet Metab 2001;74:342-4.

21 Le Maréchal C, Chen JM, Quéré I, et al. Discrimination of three mutational events that result in a disruption of the R 122 primary autolysis site of the human cationic trypsinogen (PRSS1) by denaturing high performance liquid chromatography. BMC Genet 2001;2:19.

22 Tautermann $\mathbf{G}$, Ruebsamen $\mathrm{H}$, Beck $M$, et al. R1 16C mutation of cationic trypsinogen in a Turkish family with recurrent pancreatitis illustrates genetic microheterogeneity of hereditary pancreatitis. Digestion $2001 ; 64: 226-32$.

23 Simon P, Weiss FU, Sahin-Tóth $M$, et al. Hereditary pancreatitis caused by a novel PRSS1 mutation (Arg-122 $\rightarrow$ Cys) that alters autoactivation and autodegradation of cationic trypsinogen. J Biol Chem 2002;277:5404-10

24 Pfützer R, Myers E, Applebaum-Shapiro S, et al. Novel cationic trypsinogen (PRSS1) N29T and R122C mutations cause autosomal dominant hereditary pancreatitis. Gut 2002;50:271-2

25 Teich N, Baver N, Mössner J, et al. Mutational screening of patients with nonalcoholic chronic pancreatitis: identification of further trypsinogen variants. Am J Gastroenterol 2002;97:341-6.

26 Sahin-Tóth M. Human cationic trypsinogen. Role of Asn-21 in zymogen activation and implications in hereditary pancreatitis. J Biol Chem 2000;275:22750-5

27 Sahin-Tóth M, Tóth M. Gain-of-function mutations associated with hereditary pancreatitis enhance autoactivation of human cationic trypsinogen. Biochem Biophys Res Commun 2000;278:286-9.

28 Szilágyi L, Kénesi E, Katona G, et al. Comparative in vitro studies on native and recombinant human cationic trypsins. Cathepsin $B$ is a possible pathological activator of trypsinogen in pancreatitis. J Biol Chem $2001 ; 276: 24574-80$.

29 Simon $\mathbf{P}$, Weiss FU, Sahin-Tóth $M$, et al. Hereditary pancreatitis caused by a novel PRSS 1 mutation (Arg-122 $\rightarrow$ Cys) that alters autoactivation and autodegradation of cationic trypsinogen. J Biol Chem 2002;277:5404-10

30 Kukor Z, Tóth M, Pál G, et al. Human cationic trypsinogen. $\operatorname{Arg}(117)$ is the reactive site of an inhibitory surface loop that controls spontaneous zymogen activation. J Biol Chem 2002;277:6111-17.

31 Kazal LA, Spicer DS, Brahinsky RA. Isolation of a crystalline trypsin inhibitor-anticoagulant protein from the pancreas. J Am Chem Soc 1948;70:304-40.

32 Bartelt DC, Shapanka R, Greene L. The primary structure of the human pancreatic secretory trypsin inhibitor. Amino acid sequence of the reduced S-aminoethylated protein. Arch Biochem Biophys 1977; 179:189-99.

33 Laskowski $\mathbf{M}$, Wu FC. Temporary inhibition of trypsin. J Biol Chem 1953;204:797-805.

34 Witt $\mathbf{H}$, Luck W, Hennies HC, et al. Mutations in the gene encoding the serine protease inhibitor, Kazal type 1 are associated with chronic pancreatitis. Nat Genet 2000;25:213-16.

35 Pfützer RH, Barmada NM, Brunskill APJ, et al. SPINK 1/PSTI polymorphisms act as disease modifiers in familial and idiopathic chronic pancreatitis. Gastroenterology 2000;1 19:615-23.

36 Chen JM, Mercier B, Audrézet MP, et al. Mutations of the pancreatic secretory trypsin inhibitor (PSTI) gene in idiopathic chronic pancreatitis. Gastroenterology 2001;120:1061-4.

37 Drenth JPH, te Morsche R, Jansen JBM. Mutations in serine protease inhibitor Kazal type 1 are strongly associated with chronic pancreatitis. Gut 2002;50:687-92.

38 Threadgold J, Greenhalf W, Ellis I, et al. The N34S mutation of SPINK I (PSTI) is associated with a familial pattern of idiopathic chronic pancreatitis but does not cause the disease. Gut 2002;50:675-81.
39 Chen JM, Mercier B, Audrézet MP, et al. Mutational analysis of the human pancreatic secretory trypsin inhibitor (PSTI) gene in hereditary and sporadic chronic pancreatitis. J Med Genet 2000;37:67-9.

40 Kuwata K, Hirota M, Sugita H, et al. Genetic mutations in exons 3 and 4 of the pancreatic secretory trypsin inhibitor in patients with pancreatitis. J Gastroenterol 2001;36:612-18.

41 Ockenga J, Dörk T, Stuhrmann M. Low prevalence of SPINK1 gene mutations in adult patients with chronic idiopathic pancreatitis. J Med Genet $2001 ; 38: 243-4$

42 Kaneko K, Nagasaki Y, Furukawa T, et al. Analysis of the human pancreatic secretory trypsin inhibitor (PSTI) gene mutations in Japanese patients with chronic pancreatitis. J Hum Genet 2001;46:293-7.

43 Audrézet MP, Chen JM, Le Maréchal C, et al. Determination of the relative contribution of three genes-the cystic fibrosis transmembrane conductance regulator gene, the cationic trypsinogen gene, and the pancreatic secretory trypsin inhibitor gene-to the etiology of idiopathic chronic pancreatitis. Eur J Hum Genet 2002;10:100-6.

44 Sharer N, Schwarz M, Malone G, et al. Mutations of the cystic fibrosis gene in patients with chronic pancreatitis. N Engl J Med 1998;339:645-52

45 Cohn JA, Friedman K, Noone P, et al. Relation between mutations of the cystic fibrosis gene and idiopathic pancreatitis. N Engl J Med 1998;339:653-8

46 Bank S, Marks IN, Novis B. Sweat electrolytes in chronic pancreatitis. Am J Dig Dis 1978;23:178-81.

47 Nakamura K, Sarles H, Payan $\mathrm{H}$. Three-dimensional reconstruction of the pancreatic ducts in chronic pancreatitis. Gastroenterology 1972;62:942-9

48 de Angelis C, Valente G, Spaccapietra M, et al. Histological study of alcoholic, nonalcoholic, and obstructive chronic pancreatitis. Pancreas 1992; 7:193-6.

49 Shwachman H, Lebenthal E, Khaw W. Recurrent acute pancreatitis in patients with cystic fibrosis with normal pancreatic enzymes. Pediatrics 1975;55:86-94

50 Atlas AB, Orenstein SR, Orenstein DM. Pancreatitis in young children with cystic fibrosis. J Pediatr 1992;120:756-9.

51 Kiesewetter S, Macek M Jr, Davis C, et al. A mutation in CFTR produces different phenotypes depending on chromosomal background Nat Genet 1993;5:274-8.

52 Noone PG, Zhou Z, Silverman LM, et al. Cystic fibrosis gene mutations and pancreatitis risk: relation to epithelial ion transport and trypsin inhibitor gene mutations. Gastroenterology 2001;121:1310-19.

53 Hutchison DCS. $\alpha_{1}$-antitrypsin deficiency in Europe: geographical distribution of Pi types S and Z. Respir Med 1998;92:367-77.

54 Novis BH, Young GO, Bank S, et al. Chronic pancreatitis and alpha-1-antitrypsin. Lancet 1975;ii:748-9.

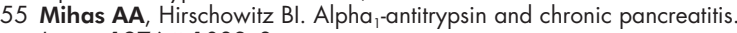
Lancet 1976;ii:1032-3

56 Braxel C, Versieck J, Lemey G, et al. Alpha ${ }_{1}$-antitrypsin in pancreatitis. Digestion 1982;23:93-6.

57 Lankisch PG, Koop H, Winckler K, et al. $\alpha_{1}$-antitrypsin in pancreatic diseases. Digestion 1978;18:138-40.

58 Haber PS, Wilson JS, McGarity BH, et al. $\alpha_{1}$ antitrypsin phenotypes and alcoholic pancreatitis. Gut $1991 ; 32: 945-8$

59 Witt $\mathbf{H}$, Kage A, Luck W, et al. $\alpha 1$-antitrypsin genotypes in patients with chronic pancreatitis. Scand J Gastroenterol 2002;37:356-9.

60 Teich N, Walther K, Bödeker H, et al. Relevance of variants in serum antiproteinases for the course of chronic pancreatitis. Scand J Gastroenterol 2002;37:360-5

61 Larsson C. Natural history and life expectancy in severe alpha-1-antitrypsin deficiency, Pi Z. Acta Med Scand 1978;204:34551

62 Matthew P, Wyllie R, Caulfield M, et al. Chronic pancreatitis in late childhood and adolescence. Clin Pediatr 1994;33:88-94.

63 Witt H, Hennies HC, Becker M. SPINK1 mutations in chronic pancreatitis (letter). Gastroenterology 2001;120:1060-1.

64 Rinderknecht H. Pancreatic secretory enzymes. In: Go VLW, et al, eds) The pancreas: biology, pathobiology, and disease. New York: Raven, 1993:219-51

65 Laskowski M Jr, Kato I. Protein inhibitors of proteinases. Annu Rev Biochem 1980;49:593-626.

66 Rinderknecht $\mathbf{H}$. Activation of pancreatic zymogens. Normal activation, premature intrapancreatic activation, protective mechanisms against inappropriate activation. Dig Dis Sci 1986;31:314-21.

67 Freedman SD, Blanco P, Shea JC, et al. Mechanisms to explain pancreatic dysfunction in cystic fibrosis. Gastroenterol Clin North Am 2000;84:657-64

68 Ammann RW. A clinically based classification system for alcoholic chronic pancreatitis: summary of an international workshop on chronic pancreatitis. Pancreas 1997; 14:215-21.

69 Teich N, Mössner J, Keim V. Screening for mutations of the cationic trypsinogen gene: are they of relevance in chronic alcoholic pancreatitis? Gut 1999;44:413-16

70 Keim V, Hoffmeister A, Teich N, et al. The pancreatitis-associated protein in hereditary and chronic alcoholic pancreatitis. Pancreas 1999:19:248-54

71 Norton ID, Apte MV, Dixson H, et al. Cystic fibrosis genotypes and alcoholic pancreatitis. J Gastroenterol Hepatol 1998; 13:496-9.

72 Haber P, Wilson J, Apte M, et al. Individual susceptibility to alcoholic pancreatitis: still an enigma. J Lab Clin Med 1995;125:305-12.

73 Witt $\mathbf{H}$, Luck W, Becker $M$, et al. Mutation in the SPINK 1 trypsin inhibitor gene, alcohol use, and chronic pancreatitis. JAMA 2001;285:2716-17. 
74 Rinderknecht $\mathbf{H}$, Stace NH, Renner IG. Effects of alcohol abuse on exocrine pancreatic secretion in man. Dig Dis Sci 1985;50:65-71. 75 Sarner M, Cotton PB. Classification of pancreatitis. Gut 1984;25:756-9

76 Sarles H, Adler G, Dani R, et al. The pancreatitis classification of Marseilles-Rome 1988. Scand J Gastroenterol 1989:24:641-2.

77 Sarles H, Adler G, Dani R, et al. Classifications of pancreatitis and definition of pancreatic diseases. Digestion 1989;43:234-6.

78 Comfort MW, Gambill EE, Baggenstoss AH. Chronic relapsing pancreatitis: a study of 29 cases without associated disease of the biliary or gastrointestinal tract. Gastroenterology 1946;6:239-85

79 Riordan JR, Rommens JM, Kerem B, et al. Identification of the cystic fibrosis gene: cloning and characterization of complementary DNA. Science 1989;245: 1066-73.

80 Kerem BS, Rommens JM, Buchanan JA, et al. Identification of the cystic fibrosis gene: genetic analysis. Science 1989;245:1073-80.

81 Zielenski J, Rozmahel R, Bozon D, et al. Genomic DNA sequence of the cystic fibrosis transmembrane conductance regulator (CFTR) gene. Genomics 1991;10:214-28.

82 Riordan JR. The cystic fibrosis transmembrane conductance regulator. Annu Rev Physiol 1993;55:609-30.

83 Sheppard DN, Welsh M. Structure and function of the CFTR chloride channel. Physiol Rev 1999;79:S23-45.

84 The Cystic Fibrosis Genetic Analysis Consortium. Population variation of common cystic fibrosis mutations. Hum Mutat 1994:4:167-77

85 Welsh M, Smith A. Molecular mechanisms of CFTR chloride channel dysfunction in cystic fibrosis. Cell 1993:73:1251-4.

86 Wilschanski M, Zielenski J, Markiewicz D, et al. Correlation of sweat chloride concentration with classes of the cystic fibrosis transmembrane conductance regulator gene mutations. J Pediatr 1995;127:705-10.

87 Mickle JE, Cutting GR. Genotype-phenotype relationships in cystic fibrosis. Med Clin North Am 2000:84:597-607.

88 Cheng SH, Gregory RJ, Marshall J, et al. Defective intracellular transport and processing of CFTR is the molecular basis of most cystic fibrosis. Cell 1990;63:827-34.

89 Fulmer SB, Schwiebert EM, Morales MM, et al. Two cystic fibrosis transmembrane conductance regulator mutations have different effects on both pulmonary phenotype and regulation of outwardly rectified chloride currents. Proc Natl Acad Sci USA 1995;92:6832-6.

90 The Cystic Fibrosis Genotype-Phenotype Consortium. Correlation between genotype and phenotype in patients with cystic fibrosis. N Eng J Med 1993:329:1308-13

91 Ferrari M, Colombo C, Sebastio G, et al. Cystic fibrosis patients with liver disease are not genetically distinct. Am J Hum Genet 1991;48:815-16.

92 Duthie A, Doherty DG, Williams C, et al. Genotype analysis for delta F508, G551D and R553X mutations in children and young adults with cystic fibrosis with and without chronic liver disease. Hepatology 1992;15:660-4

93 Colombo C, Apostolo MG, Ferrari M, et al. Analysis of risk factors for the development of liver disease associated with cystic fibrosis. J Pediat 1994;124:393-9.

94 Wilschanski $\mathbf{M}$, Rivlin J, Cohen S, et al. Clinical and genetic risk factors for cystic fibrosis-related liver disease. Pediatrics 1999;103:52-7.

95 Waters DL, Dorney SF, Gruca MA, et al. Hepatobiliary disease in cystic fibrosis patients with pancreatic sufficiency. Hepatology 1995;21:963-9.

96 Duthie A, Doherty DG, Donaldson PT, et al. The major histocompatibility complex influences the development of chronic liver disease in male children and young adults with cystic fibrosis. J Hepatol 1995;23:532-7.

97 Gabolde M, Hubert D, Guilloud-Bataille M, et al. The mannose binding lectin gene influences the severity of chronic liver disease in cystic fibrosis. J Med Genet 2001;38:310-11.

98 Holslcaw D, Eckstein $\mathrm{H}$, Nixon HH. Meconium ileus: a 20 year review of 109 cases. Am J Dis Child 1965;109:101-13.

99 Kerem E, Corey M, Kerem B, et al. Clinical and genetic comparisons of patients with cystic fibrosis, with or without meconium ileus. J Pediatr 1989:114:767-73.

100 Kristidis P, Bozon D, Corey M, et al. Genetic determination of exocrine pancreatic function in cystic fibrosis. Am J Hum Genet 1992;50: $1178-84$

101 Zielenski J, Corey M, Rozmahel R, et al. Detection of a cystic fibrosis modifier locus for meconium ileus on human chromosome 19q13. Na Genet 1999:22:128-9.

102 Rohlfs EM, Shaheen NJ, Silverman LM. Is the hemochromatosis gene a modifier locus for cystic fibrosis? Genet Test 1998;2:85-8

103 Lester LA, Kraut J, Lloyd-Still J, et al. Delta F508 genotype does not predict disease severity in an ethnically diverse cystic fibrosis population. Pediatrics 1994:93:114-18.

104 Koch C, Cuppens H, Rainisio M, et al. European Epidemiologic Registry of Cystic Fibrosis (ERCF): comparison of major disease manifestations between patients with different classes of mutations. Pediatr Pulmonol 2001;31:1-12.

105 Aron Y, Polla BS, Bienvenu T, et al. HLA class II polymorphism in cystic fibrosis: a possible modifier of pulmonary phenotype. Am J Respir Crit Care Med 1999;159:1464-8.

106 Döring G, Krogh-Johansen H, Weidinger S, et al. Allotypes of alpha 1-antitrypsin in patients with cystic fibrosis, homozygous and heterozygous for deltaF508. Pediatr Pulmonol 1994:18:3-7.

107 Mahadeva R, Westerbeek RC, Perry DJ, et al. Alphal-antitrypsin deficiency alleles and the Taq-I G->A allele in cystic fibrosis lung disease. Eur Respir J 1998;11:873-9.
108 Mahadeva $\mathbf{R}$, Stewart S, Bilton D, et al. Alpha-1 antitrypsin deficiency alleles and severe cystic fibrosis lung disease. Thorax 1998;53:1022-4.

09 Mahadeva R, Sharples L, Ross-Russell RI, et al. Association of alpha(1)-antichymotrypsin deficiency with milder lung disease in patients with cystic fibrosis. Thorax 2001;56:53-8.

110 Wilson AG, Symons JA, McDowell T, et al. Effects of a polymorphism in the human tumor necrosis factor alpha promoter on transcriptional activation. Proc Natl Acad Sci USA 1997;94:3195-9.

111 Hull J, Thomson AH. Contribution of genetic factors other than CFTR to disease severity in cystic fibrosis. Thorax 1998:53:1018-21.

112 Ignotz RA, Massague J. Transforming growth factor-beta stimulates the expression of fibronectin and collagen and their incorporation into the extracellular matrix. J Biol Chem 1986;261:4337-45.

113 Arkwright PD, Laurie S, Super M, et al. TGF-beta(1) genotype and accelerated decline in lung function of patients with cystic fibrosis. Thorax 2000;55:459-62

114 Awad MR, El-Gamel A, Hasleton P, et al. Genotypic variation in the transforming growth factor-betal gene: association with transforming growth factor-beta 1 production, fibrotic lung disease, and graft fibrosis after lung transplantation. Transplantation 1998;66:1014-20.

115 Seidegard J, Vorachek WR, Pero RW, et al. Hereditary differences in the expression of the human glutathione transferase active on trans-stilbene oxide are due to a gene deletion. Proc Nat Acad Sci USA 1988;85:7293-7.

116 Strange RC, Matharoo B, Faulder GC, et al. The human glutathione S-transferases: a case-control study of the incidence of the GST1 0 phenotype in patients with adenocarcinoma. Carcinogenesis $1991 ; 12: 25-8$

117 Heagerty AH, Fitzgerald D, Smith A, et al. Glutathione S-transferase GSTM1 phenotypes and protection against cutaneous tumours. Lance 1994;343:266-8.

118 Baranov VS, Ivaschenko T, Bakay B, et al. Proportion of the GSTM1 0/0 genotype in some Slavic populations and its correlation with cystic fibrosis and some multifactorial diseases. Hum Genet 1996;97:516-20.

119 Strange RC, Faulder CG, Davis BA, et al. The human glutathione S-transferases: studies on the tissue distribution and genetic variation of the GST1, GST2 and GST3 isozymes. Ann Hum Genet 1984;48:1 1-20.

120 Balfour-Lynn IM, Laverty A, Dinwiddie R. Reduced upper airway nitric oxide in cystic fibrosis. Arch Dis Child 1996;75:319-22

121 Grasemann H, Knauer N, Büscher R, et al. Airway nitric oxide levels in cystic fibrosis patients are related to a polymorphism in the neuronal nitric oxide synthase gene. Am J Respir Crit Care Med 2000;162:2172-6

122 Garred P, Pressler T, Madsen $\mathrm{HO}$, et al. Association of mannose-binding lectin gene heterogeneity with severity of lung disease and survival in cystic fibrosis. J Clin Invest 1999;104:431-7.

123 Gabolde M, Guilloud-Bataille M, Feingold J, et al. Association of varian alleles of mannose binding lectin with severity of pulmonary disease in cystic fibrosis: cohort study. BM 1999;319:1166-7.

124 Hawgood S, Poulain FR. The pulmonary collectins and surfactant metabolism. Annu Rev Physiol 2001;63:495-519.

125 Sumiya M, Super M, Tabona $P$, et al. Molecular basis of opsonic defect in immunodeficient children. Lancet 1991;337:1569-70.

126 Garred P, Madsen HO, Hofmann B, et al. Increased frequency of homozygosity of abnormal mannan-binding protein alleles in patients with suspected immunodeficiency. Lancet 1995;346:941-3.

127 Summerfield JA, Ryder S, Sumiya M, et al. Mannose binding protein gene mutations associated with unusual and severe infections in adults. Lancet 1995;345:886-9.

128 Garred $\mathbf{P}$, Madsen HO, Balslev U, et al. Susceptibility to HIV infection and progression of AIDS in relation to variant alleles of mannose-binding lectin. Lancet 1997;349:236-40

129 Lipscombe RJ, Sumiya M, Hill AV, et al. High frequencies in African and non-African populations of independent mutations in the mannose binding protein gene. Hum Mol Genet 1992;1:709-15.

130 Madsen HO, Garred P, Kurtzhals JA, et al. A new frequent allele is the missing link in the structural polymorphism of the human mannan-binding protein. Immunogenetics 1994;40:37-44

131 Madsen HO, Garred P, Thiel S, et al. Interplay between promoter and structural gene variants control basal serum level of mannan-binding protein. J Immunol 1995:155:3013-20.

132 Madsen HO, Satz ML, Hogh B, et al. Different molecular events result in low protein levels of mannan-binding lectin in populations from Southeast Africa and South America. J Immunol 1998;161:3169-75.

133 Kaplan E, Shwachman H, Perlmutter AD, et al. Reproductive failure in males with cystic fibrosis. N Engl J Med 1968;279:65-9.

134 Dumur V, Gervais R, Rigot JM, et al. Abnormal distribution of CF delta F508 allele in azoospermic men with congenital aplasia of epididymis and vas deferens. Lancet 1990;336:512.

135 Culard JF, Desgeorges M, Costa P, et al. Analysis of the whole CFTR coding regions and splice junctions in azoospermic men with congenital bilateral aplasia of epididymis or vas deferens. Hum Genet 1994;93:467-70

136 Mercier B, Verlingue C, Lissens W, et al. Is congenital bilateral absence of vas deferens a primary form of cystic fibrosis? Analyses of the CFTR gene in 67 patients. Am J Hum Genet 1995;56:272-7.

137 Costes B, Girodon E, Ghanem N, et al. Frequent occurrence of the CFTR intron 8 (TG)n 5T allele in men with congenital bilateral absence of the vas deferens. Eur J Hum Genet 1995;3:285-93.

138 Casals T, Bassas L, Ruiz-Romero J, et al. Extensive analysis of 40 infertile patients with congenital absence of the vas deferens: in 50\% of cases only one CFTR allele could be detected. Hum Genet 1995;95:205-1 1 
139 Chillon M, Casals T, Mercier B, et al. Mutations in the cystic fibrosis gene in patients with congenital absence of the vas deferens. N Engl J Med 1995;332:1475-80.

140 Zielenski J, Patrizio P, Corey M, et al. CFTR gene variant for patients with congenital absence of vas deferens. Am J Hum Genet 1995:57:958-60.

141 Chu CS, Trapnell BC, Murtagh JJ Jr, et al. Variable deletion of exon 9 coding sequences in cystic fibrosis transmembrane conductance regulator gene mRNA transcripts in normal bronchial epithelium. EMBO J 1991;10:1355-63.

142 Chu CS, Trapnell BC, Curristin S, et al. Genetic basis of variable exon 9 skipping in cystic fibrosis transmembrane conductance regulator mRNA. Nat Genet 1993;3:151-6.

143 Strong TV, Wilkinson DJ, Mansoura MK, et al. Expression of an abundant alternatively spliced form of the cystic fibrosis transmembrane conductance regulator (CFTR) gene is not associated with a cAMP-activated chloride conductance. Hum Mol Genet 1993;2:225-30.

144 Poller W, Faber JP, Scholz S, et al. Sequence analysis of the cystic fibrosis gene in patients with disseminated bronchiectatic lung disease. Application in the identification of a cystic fibrosis patient with atypical clinical course. Klin Wochenschr 1991;69:657-63.

145 Pignatti PF, Bombieri C, Marigo C, et al. Increased incidence of cystic fibrosis gene mutations in adults with disseminated bronchiectasis. Hum Mol Genet 1995:4:635-9.

146 Pignatti PF, Bombieri C, Benetazzo M et al. CFTR gene variant IVS8-5T in disseminated bronchiectasis. Am J Hum Genet 1996;58:889-92.

147 Girodon E, Cazeneuve C, Lebargy F, et al. CFTR gene mutations in adults with disseminated bronchiectasis. Eur J Hum Genet 1997:5:149-55

148 Bombieri C, Benetazzo M, Saccomani A, et al. Complete mutational screening of the CFTR gene in 120 patients with pulmonary disease. Hum Genet 1998;103:718-22

149 Tzetis M, Efthymiadou A, Strofalis S, et al. CFTR gene mutations-including three novel nucleotide substitutions-and haplotype background in patients with asthma, disseminated bronchiectasis and chronic obstructive pulmonary disease. Hum Genet 2001;108:216-21.

150 Schroeder SA, Gaughan DM, Swift M. Protection against bronchial asthma by CFTR delta F508 mutation: a heterozygote advantage in cystic fibrosis. Nat Med 1995;1:703-5.

151 Mennie M, Gilfillan A, Brock DJ, et al. Heterozygotes for the delta F508 cystic fibrosis allele are not protected against bronchial asthma. Nat Med 1995; 1:978-9

152 Dahl M, Tybjaerg-Hansen A, Lange $P$, et al. DeltaF508 heterozygosity in cystic fibrosis and susceptibility to asthma. Lancet 1998;351:1911-13.
153 Lázaro C, de Cid R, Sunyer J, et al. Missense mutations in the cystic fibrosis gene in adult patients with asthma. Hum Mutat 1999; 14:510-19.

154 Casals T, Ramos MD, Gimenez J, et al. High heterogeneity for cystic fibrosis in Spanish families: 75 mutations account for $90 \%$ of chromosomes. Hum Genet 1997; 101:365-70.

155 Marchand E, Verellen-Dumoulin C, Mairesse M, et al. Frequency of cystic fibrosis transmembrane conductance regulator gene mutations and 5T allele in patients with allergic bronchopulmonary aspergillosis. Chest 2001;119:762-7.

156 Castellani C, Quinzii C, Altieri S, et al. A pilot survey of cystic fibrosis clinical manifestations in CFTR mutation heterozygotes. Genet Test 2001;5:249-54.

157 Hinson KFW, Moon AJ, Plummer NS. Bronchopulmonary aspergillosis: a review and a report of eight new cases. Thorax 1952;7:317-33.

158 Geller DE, Kaplowitz H, Light M, et al. Allergic bronchopulmonary aspergillosis in cystic fibrosis: reported prevalence, regional distribution, and patient characteristics. Scientific Advisory Group, Investigators, and Coordinators of the Epidemiologic Study of Cystic Fibrosis. Chest 1999:1 16:639-46.

159 Mastella G, Rainisio M, Harms HK, et al. Allergic bronchopulmonary aspergillosis in cystic fibrosis. A European epidemiological study. Epidemiologic Registry of Cystic Fibrosis. Eur Respir J 2000;1 6:464-71

160 Starke ID. Asthma and allergic aspergillosis in monozygotic twins. Br J Dis Chest 1985;79:295-300.

161 Shah A, Khan ZU, Chaturvedi S, et al. Concomitant allergic Aspergillus sinusitis and allergic bronchopulmonary aspergillosis associated with familial occurrence of allergic bronchopulmonary aspergillosis. Ann Allergy 1990;64:507-12.

162 Miller PW, Hamosh A, Macek M Jr, et al. Cystic fibrosis transmembrane conductance regulator (CFTR) gene mutations in allergic bronchopulmonary aspergillosis. Am J Hum Genet 1996;59:45-51.

163 Wang X, Moylan B, Leopold DA, et al. Mutation in the gene responsible for cystic fibrosis and predisposition to chronic rhinosinusitis in the general population. JAMA 2000;284:1814-19.

164 Raman V, Clary R, Siegrist KL, et al. Increased prevalence of mutations in the cystic fibrosis transmembrane conductance regulator in children with chronic rhinosinusitis. Pediatrics 2002;109:E13.

165 Hytönen $M$, Patjas $M$, Vento $\mathrm{SI}$, et al. Cystic fibrosis gene mutations AF508 and 394delTT in patients with chronic sinusitis in Finland. Acta Otolaryngol 2001;121:945-7.

166 Bombieri C, Luisetti M, Belpinati F, et al. Increased frequency of CFTR gene mutations in sarcoidosis: a case/control association study. Eur J Hum Genet 2000;8:717-20. 